Vol. 9 (3): 417-422 (2019)

\title{
IN VIVO USE OF WATERMELON SEEDS
}

\section{Eda GÜNEŞ ${ }^{1^{*}}$}

${ }^{1 *}$ Necmettin Erbakan University, Faculty of Tourism, Department of Gastronomy and Culinary Arts, Konya, Turkey;

"Corresponding Author Eda GÜNEŞ, e-mail: egunes@konya.edu.tr;

"Received March 2019; Accepted April 2019; Published July 2019;

DOI: https://doi.org/10.31407/ijees9302

\begin{abstract}
It is possible to evaluate agricultural products from seed to shell. Watermelon (Citrullus lanatus) is an important vegetable species made in the world farming watermelon, Cucubitaceae is a plant belonging to the family. It is aimed to determine the effect of watermelon seed which is natural waste on nutrition (directly and indirectly by consumption). For this purpose, the nutrients of the model organism (Drosophila melanogaster) were fed by mixing the watermelon seed (0.1-10\%). Survival rate and development time of the insect is determined. Besides the use of watermelon seeds as an alternative by-product, the impact on living beings as a waste is discussed.
\end{abstract}

Keywords: Drosophila melanogaster, Citrullus lanatus, survival rate, development time 